\title{
O CORPO DA BICHA PRETA \\ LAFAYETTE E A POLÍTICA DO DESAMOR NA LITERATURA DE CHARLAINE HARRIS
}

Nilton Milanez (UESB)

Resumo: Neste artigo discuto o modo como o corpo constrói um posicionamento social e histórico para o gay nos livros Morto até o amanhecer e Vampiros em Dallas da escritora norte-americana Charlaine Harris. Para tanto, focalizo, particularmente, as formas como um de seus personagens, Lafayette, é conduzido na trama. Sob essa perspectiva, problematizo as unidades que constroem um livro como também a relação entre a morfologia corporal e os saberes que ela produz para a circulação de discursos sobre o gay. Demonstro, portanto, como a língua materializa, na escrita de Harris, discursos em torno de uma política da segregação e do desafeto no que concerne ao amor entre rapazes.

Palavras-chave: Corpo, Gay, Discurso, Lafayette, Charlaine Harris.

Abstract: In this article I discuss the way how the body builds a social and historical position towards gay men within the books Dead until dark and Living dead in Dallas by the North American writer Charlaine Harris. Therefore, I focus particularly the modes through one of her characters, Lafayette, is conducted along the plot. Under this perspective, I problematize the units which construct a book as well as the relation between the body morphology and the knowledge it produces considering the discourse circulation about gay. I demonstrate, then, how language in the writings of Harris materializes discourses on a segregating and disaffection politics concerning love between guys. Keywords: Body, Gay, Discourse, Lafayette, Charlaine Harris.

\section{O CORPO DA BICHA PRETA: TESE INICIAL}

Lafayette é um jovem negro gay e trabalha na cozinha de um bar na cidade de Bon Temps, na Louisiana, nos Estados Unidos. Esse personagem da escritora norte-americana 
Charlaine Harris é evocado raras vezes em seu primeiro livro, Morto até o anoitecer, e vai ter seu grand finale muito rapidamente no segundo livro da autora, Vampiros em Dallas. Os livros de Harris se tornaram uma saga. Quatorze livros escritos entre 2001 e 2013, que suscitaram a série televisiva sobre vampiros na $\mathrm{HBO}$, recebendo o nome de True Blood, com veiculação na TV brasileira em 2013. Diferentemente da vida longa de Lafayette na TV, nos livros sua morte é prematura. A ruptura entre as imagens da TV e as letras do livro me chamaram a atenção.

Se Lafayette já me despertava simpatia em True Blood, nos livros a empatia teórico-analítica foi ainda maior. Harris introduz uma pequena janela para olharmos Lafayette e o tira do enredo inesperadamente. A vida de Lafayette é um efeito dos pequenos grandes sujeitos que possibilitam uma contorção histórica, um alinhamento com as problemáticas e discursos que circulam sobre o gay hoje. Tão pouco presente na narrativa, tão intensamente marcante em nossa história cotidiana, serão as modalidades de apresentação do corpo de Lafayette, e nele sua pele e exercício de sexualidade, que guiarão este trabalho.

Proponho pensar com o corpo de Lafayette a maneira como ele foi dado a ler pelas mãos de Harris. Um corpo 
em específico do qual destaco algumas questões. Primeiro, compreender quais as articulações do personagem com a unidade material da obra. Feita esta delimitação, segundo, problematizar a noção de corpo que se instala como um subconjunto no interior dos dois primeiros livros da autora. E, terceiro, investigar ligeiramente quais fenômenos históricos de hoje emergem da configuração desse campo literário e dos discursos que promove.

Vou seguir, portanto, esse percurso teórico-analítico tomando como fundamento os estudos de Michel Foucault para pensar o amor, a política e a história da vida, ao mesmo tempo comum e bem incomum de Lafayette, na nossa sociedade de alguns pseudo gritos de diversidade em uma literatura que se pretende politicamente correta, acabando por revelar-se controladora e normalizante do espaço sobre os movimentos do corpo afetivo-sexualizado entre homens.

\section{LAFAYETTE: COMO, O QUÊ E A UNIDADE DE UM LIVRO}

Lafayette não está no título do livro Morto até o anoitecer. A referência dá destaque ao vampiro Bill Compton, que se coloca como vivo, em pé, apenas depois do sol se pôr. Também não se encaixa no marketing literário das chamadas da capa logo abaixo do título Vampiros, assassinatos inexplicáveis, mistério, amor. Entre as primeiras linhas 
e o ponto final de um livro de 12 capítulos e 314 páginas, Lafayette vai surgir apenas no capítulo 3, com brevíssimas retomadas nos capítulos 4, 6 e 10. Em Vampiros em Dallas, seu lugar de destaque é o da sua própria morte, no capítulo 1. Seu cadáver é posto em cena dentro do carro de um policial nos fundos do bar em que trabalhava. E assim desaparecerá. Mas as coisas não são simples desse jeito. Lafayette, ao ser morto por Harris, dá vida à condição e à condução de seu corpo ao longo da história.

Com isso, vamos ver que o personagem não se limita às margens dos dois livros. A nitidez de sua compleição e as maneiras de mostrá-lo passam não apenas por sua formatação interna, mas também por um feixe de encadeamentos que vão construir o campo dos discursos materializados pelas posições dadas por Harris. Cria-se, assim, o "nó em uma rede" (FOUCAULT, 2008, p. 25), que não deixa Lafayette se enclausurar nos limites de um livro, deslocando-o para os cantos da nossa história do presente efetivo das homossexualidades.

Nessa baila, recortar um personagem dentro de um subconjunto de romances traz uma questão teórica, que é o da própria configuração da obra, os limites e descontinuidades entre a vida real das letras e a real vida dos corpos que as 
leem. Essa virtualidade do real nas ondulações de uma análise histórica nos faz refletir sobre como proceder a esta análise e que problemas teóricos levantar. Não se trata, portanto, de uma descrição considerando uma análise linguística.

De um lado, trato de estabelecer como vou fazer meu trabalho e verificar as leis que fazem com que o corpo negro de Lafayette restaure o que Foucault $(2008$, p. 30) denominou de "enunciados possíveis" para se problematizar a finitude de um conjunto de regras, que vão organizar a raridade e a singularidade de um modo de dizer e estar no mundo. De outro, quero mostrar o que vou fazer. E aí me confronto com a análise do campo dos discursos que Lafayette fará emergir. Para isso, vou me envolver nas condições de existência do aparecimento do personagem, estabelecendo seus limites dentro da obra, não sem deixar de fixar as relações com outras modalidades enunciativas a que se liga e a que se exclui.

Posto isso, a unidade material de um livro não se revela pela sua espessura, sua estrutura, seu sistema linguístico. Por outro lado, se faz presente pela sua espessura, a histórica, pela sua estrutura, a descrição de acontecimentos no campo do discurso, e por seu sistema, aquele que indica formas para classificar, normatizar e institucionalizar. É nesses lugares que Lafayette vai estar 
e que vamos encontrá-lo vivo até depois de sua morte, contraditoriamente não um vampiro, um humano, pois, não de letra e papel, mas de carne, sangue e história.

\section{MORFOLOGIA CORPORAL E DISCURSO: O CASO DE LAFAYETTE}

Ao se problematizar o corpo, a primeira questão que surge é a de qual corpo estamos falando. Inicialmente, poderíamos pensar que se trata do corpo biológico, mas, no caso deste estudo em específico, estamos diante de uma modalidade literária que, em vários momentos, descreve, detalha e coloca em evidência o corpo do personagem. Mais uma vez se impõe aí uma questão de método.

O procedimento de leitura a ser tomado é o a da compreensão morfológica corporal do objeto estudado. Entendo morfologia corporal como os traços, índices e marcas que relevam o corpo, os gestos, as roupas e as falas a fim de arquitetar a compleição física e o estatuto social de um sujeito. $\mathrm{O}$ detalhe mínimo, aquele que muitas vezes passa despercebido, é o foco da investigação de uma morfologia corporal (MILANEZ, 2012). Tomo de empréstimo em Ginzburg (1990), portanto, o procedimento de observação das raízes

e dos detalhes para formação do campo de análise. Dessa maneira, a apresentação da morfologia do corpo em estudo 
se transforma em um exame clínico que indica a incidência de nosso olhar sobre determinadas partes específicas do corpo, como se ele pudesse ser anatomicamente desmembrado. É claro que esse tipo de análise morfológica é considerado sob uma perspectiva metonímica, abrindo as portas para a construção dos discursos sobre o corpo.

Esse levantamento morfológico dado a ver pela materialidade linguística carece de uma atitude de descrição do objeto. Não estou falando aqui de uma mera descrição linguística do vocabulário utilizado para compor a configuração do corpo do sujeito, mas compreender determinadas formulações, que vão fazer despontar o regime do corpo enquanto objeto, ou seja, a maneira pela qual ele se organiza, se ordena e se hierarquiza. Dessa feita, não são as palavras que configuram um modo de pensar, não se trata da língua enquanto significante, mas de "práticas que formam sistematicamente os objetos de que falam" (FOUCAULT, 2008, p. 55). Portanto, a descrição não está no nível linguístico. Ela está na materialidade linguística enquanto existência histórica, cercada de práticas, de maneiras de viver, de ver a vida e de orientar os corpos, orquestrados por um sujeito determinado em uma dada época. 
Vou estabelecer, então, um corpus composto de formulações que, em seu conjunto, passarão primeiramente a organizar um campo regular de formações sobre o corpo, a partir de um modo de designação de seus traços constituintes para, depois, alargar seus canteiros discursivos do interior da obra para sua exterioridade histórica. Ainda destaco que, apesar de o conjunto, que vou mostrar, dar a impressão de ser reduzido, ele apresenta em grande parte os poucos e muito significativos índices da configuração morfológica corporal de Lafayette no interior dos livros observados. O encadeamento das posições atribuídas a Lafayette farão emergir posições em relação à instância de controle, circulação e produção de discursos sobre o sujeito gay. Eis algumas maneiras pelas quais Lafayette nos é apresentado:

Lafayette pôs dois pratos na portinhola de serviço. Ele piscou para mim com um agitar de seus cílios grossos e postiços. Lafayette usa um monte de maquiagem. Eu estava tão acostumada com ele que deixara de pensar nisso. (HARRIS, 2007, p. 101)

- Eu pensei que você fosse dizer que estava saindo com um negro, mas você me arrumou um ainda melhor, né, garota? - Lafayette disse, pegando na ponta das unhas esmaltadas. (HARRIS, 2007, p. 163)

Lafayette era uma sinfonia de cores: 
estava usando uma camiseta de alças finas de cor fúcsia, jeans roxo-escuro, sandálias de tiras de couro vermelhas, e tinha uma espécie de sombra framboesa nas pálpebras. (HARRIS, 2007, p. 230)

O corpo de Lafayette, o cozinheiro de um dos turnos no Merlotte's havia sido depositado no banco de trás. Estava nu. Foi o pé magro e moreno de Lafayette, com as unhas pintadas de carmim, que me impediu de fechar a porta. (HARRIS, 2009, p.14)

Charlaine Harris vai aos poucos e lentamente introduzindo Lafayette. Seu invólucro corporal é algo que salta aos olhos nas escolhas feitas pela autora. Com efeito, ela dá uma visibilidade bastante especial ao corpo de Lafayette, tornando sua superfície corporal, para usar uma expressão de Foucault (2009, p. 13), um "corpo absolutamente visível". A exposição de detalhes dessa visibilidade é construída com bases sobre um corpo que foi examinado e ao qual foi impresso marcas da historicidade de um certo tipo de comportamento gay. A interrogação que parece se colocar é em torno do deslocamento de um portar-se sob padrões masculinos pré-estabelecidos. Como essa modalidade de corpo é esquadrinhada?

Harris mostra um personagem que é visto por partes e em cortes. A materialidade linguística produz, assim, imagens 
que se apresentam como se fossem planos-detalhes em uma tela de cinema. O corpo proposto pelas letras se transmuta, então, em imagem mental. Nessa tela vemos se amplificar o rosto, as mãos e os pés de Lafayette.

O rosto é maquiado, as unhas das mãos e dos pés são pintadas. O corpo é coberto por roupas que poderiam estar adequadas a um homem, mas no engajamento das cores das pálpebras e das unhas, seguidos de seus gestos reconhecidamente de mulher em nossa cultura, cria-se um efeito, por associação, de que aquelas roupas, e também os calçados, não fariam parte da ordem da vestimenta de um homem heterossexual. A imagem corporal dada a ver, se quer ligada a uma identidade específica. Assim, a história morfológica do corpo de Lafayette se lança em uma política de identidade especificamente gay, orientada por um olhar compulsoriamente míope.

A questão se torna significativa à medida que a força identitária que escorrega pelo discurso de Harris poderia ser compreendida como um lugar de força criativa e de recriação do corpo. Essa seria uma atitude de consideração do exercício do sujeito e do domínio e gerenciamento de seu próprio corpo em adequação a seu sentimento interior. Entretanto, o que teremos na produção de Harris não é a 
alavanca de uma resistência. Toda a inventividade possível do sujeito é colocada por terra quando entra em choque com os protagonistas da narrativa: Bill Compton, um vampiro forte, ativo, calculista, machista, tradicional e sua amada Sookie Stackhouse, de uma beleza de padrão norteamericano sempre colocado em relevo. Nesses termos, teremos como resultado "um contexto cultural que define o homossexual contra o heterossexual", segundo os estudos de Sedgwick (1985, p. 35) sobre desejo e homossocialidade do homem na literatura inglesa.

O casalzinho da América são, de um lado, os espelhamentos da virilidade, da força e, de outro, da feminilidade, da intuição e da beleza, ou seja, arquétipos caricaturais para a posição do homem e da mulher em uma rede de intrincamentos definitivamente heterossexuais, indicando uma simetria da normatividade entre os gêneros. A posição de Lafayette é, portanto, determinada pela relação e pelos jogos entre os outros personagens que, neste caso, o colocam em um lugar nada confortável, atribuindo-lhe a posição como sujeito de uma desordenação sexual. Esse quadro empurra Lafayette para a margem, tornando seu corpo um lugar para o exercício da disciplina de uma heterossexualidade compulsória imposta em Morto até o amanhecer e Vampiros em Dallas. 
Esse tipo de efeito se arquiteta por meio de uma desvirilização de Lafayette, despindo-o com atributos tomados não como uma possibilidade de estar no mundo, mas sob o jugo de uma valoração que grita alto e parece condenar uma feminilidade excessiva para um homem. O colapso da virilidade do corpo, seguindo a reflexão de Courtine (2011, p. 10) acarreta em "vulnerabilidade corporal" e "falência moral". Nesse implícito jogo da condenação do comportamento de Lafayette emerge, então, um outro aspecto possível para o corpo, a sua invisibilidade. Quando falo desta forma de invisibilidade, estou me referindo àquilo que não está dito na maneira com que Lafayette é mostrado, mas sobre as condições que dela depreendem ao colocarmos o jovem gay em rede na trama. Assim, o corpo social se desestabiliza e o sujeito é identificado por uma moral do desconserto.

Sob essa lupa, o corpo de Lafayette vai acendendo discursos reacionários, que colocam em cheque toda a pretensa problematização de Harris em torno da inclusão das diferenças em um mundo no qual os vampiros podiam "sair do caixão" (HARRIS, 2007, p. 7) e viver junto com os humanos. O pseudo discurso de Harris sobre a diversidade implode de sua obra e reafirma o marketing de uma literatura 
que clama por ser reconhecida dentro das luzes de um viver politicamente correto, beirando o senso comum ao extirpar as identidades do sujeito gay, deixando-o se entrever fora da ordem do social. Harris levanta, assim, os muros da opressão e reduz a criatividade corporal de Lafayette a um freudismo de autoajuda, que vem sob o jugo da fala de Sam, dizendo que Lafayette queria ser aceito mais que qualquer coisa.

Verdade? Nas cercanias do comportamento homossexual, ao gay é impingida e reforçada a posição da ruptura da ordem. Em Morto até o amanhecer, nossa heroína, Sookie, observa dois vampiros na casa de seu namorado, Bill, e reacende a chama de uma posição censuradora para a prática afetiva do beijo entre homens no momento em que nos diz: "Malcolm puxou o homem humano para seus braços e deu-lhe um longo beijo. Eu comecei a me sentir um pouco enjoada. Esse tipo de coisa tem que ser em particular" (HARRIS, 2007, p. 77). O posicionamento que visa relegar as afetividades no espaço das luzes apagadas ilumina a indisposição social em reconhecer o amor entre pessoas do mesmo sexo. Essa atitude elege um vinco dicotômico entre amor heterossexual e amor homossexual em um falso paraíso das diferenças.

E essa posição está atrelada à instituição de quem pronuncia tal enunciação. A jovem Sookie Stackhouse, assim 
se autodeclara, sob a caneta-marionete de Harris: "Sou loura, de olhos azuis, tenho 25 anos, minhas pernas são fortes e meu peito é volumoso, e tenho uma cinturinha de vespa" (HARRIS, 2007, p. 7). A dita verdade instaurada pelo universo criado por Harris é, portanto, disciplinadora e normativa. O corpo que ela coloca em vigência é o socialmente aceito como belo e desejável, um corpo que se manifesta como procedimento de produção para a verdade do sexo, "procedimentos destinados a esquivar a verdade insuportável e excessivamente perigosa sobre o sexo" (FOUCAULT, 1999, p. 53). O perigo é que essa verdade é de uma possibilidade homogênea, autoritariamente restrita a uma forma de vida, heterossexual, que não se revela em suas multiplicidades de desejos, funcionando como uma maneira de submissão das práticas e afetividades entre sexos iguais.

Nesse sentido, o corpo domesticado de Sookie Stackhouse para o amor entre homem e mulher instaura uma ditadura de norma sexual, desconfigurando o corpo negro de Lafayette, relegando-o à subserviência e à segregação racial. O branco se torna, portanto, o lugar da norma a ser adotada e da disciplina a ser seguida, enquanto o negro se associa à hierarquização contaminada de apreciações/ depreciações étnico-sexuais. 
Os posicionamentos que se desejam estabilizados para estes corpos são os modos pelos quais o discurso da interdição do amor entre homens vai se instalando e ganhando terreno no decorrer da narrativa de Harris. O inter-relacionamento entre as disponibilidades corporais dos personagens é que vai produzindo um discurso do corpo útil para os afetos e descartando os corpos indesejáveis para os laços amorosos entre pessoas do mesmo sexo.

As produções literárias de Harris, neste sentido, ganham suas dimensões históricas e arremessam os corpos na rede dos discursos. Os nervos do discurso são, então, tecidos pelo atravessamento de saberes e sua incrustação nos corpos fictícios faz deles corpos históricos da realidade cotidiana de nossas relações amorosas.

\section{MECANISMOS DE SABER DO CORPO: O ESCANTEIO}

Pudemos seguir até aqui a orientação de um campo discursivo que circunda o gay em um domínio no qual se juntam o corpo, a sexualidade e segregação. Gostaria de continuar a perseguir essa linha sinuosa e compreender a "estreiteza e singularidade de sua situação" (FOUCAULT, 2008, p. 31). A estreiteza, nesse caso, faz referência ao fio regular que se repete no discurso que deflagra por meio da condução da vida de Lafayette, ou seja, um posicionamento 
fixado e inflexível para o sujeito gay. Já a singularidade detona o lugar único do sujeito-personagem em questão, isto é, os lugares sociais que lhe são atribuídos a partir da maneira como Lafayette pode ser olhado, visto e observado. A situação a qual me refiro e que vou discutir agora é a vertente que estabelece as condições de existência do campo discursivo no qual se trava a batalha de uma posição gay e que, ao mesmo tempo, constrói o modo de vermos esse posicionamento.

O corpo de Lafayette é tomado como instrumento para o funcionamento de mecanismos de gestão do corpo. Harris apresenta elementos que controlam uma forma de gerenciamento do corpo do gay, encaminhando-nos para uma visão muito bem demarcada por um conjunto de saberes em torno do sujeito gay. E isso será materializado nos modos de Lafayette ver os outros e ser visto por eles. Pontuo, portanto, aqui, um dos posicionamentos nesse jogo de olhar, o escanteio, a fim de discutir como certas instâncias de poder do olhar de Harris fixam um lugar para os gays tanto sobre eles quanto em relação a eles. Vejamos quais discursos se depreendem de algumas formações que Harris constrói para Lafayette.

Através da janela da pequena cozinha eu via Lafayette Reynold, o cozinheiro, 
preparando hambúrgueres e virando uma cesta de fritas em óleo fervente. (HARRIS, 2007, p. 100)

Eu vi Lafayette espiando lá da portinhola em franca admiração, misturada a uma boa dose de medo. (HARRIS, 2007, p. 166)

- Você está arrasando, garota! exclamou Lafayette entusiasticamente. Onde foi que você arranjou este vestido? (HARRIS, 2007, p. 111)

A constituição do sujeito gay, materializado por Lafayette, é formada em correlação com a forma de enunciação do outro. A maneira como Lafayette é flagrado pelo outro lhe atribui nas formulações acima lugares fortuitos e breves, visto pela "janela da pequena cozinha". A Lafayette cabe o lugar mínimo, o do encarceramento na cozinha, sob a perspectiva do outro. Soma-se a isso a separação dos físicos. A visão sobre Lafayette surge de uma perspectiva que chamaria de o lado de cá, colocando-o, separadamente, do lado de lá. O limite dos corpos pelo espaço que ocupa, portanto, não é figurativo, mas detona a presença de lugares sociais determinados. Desse jeito, Lafayette é olhado de escanteio.

O modo de olhar, assim, configura um mecanismo de saber sobre o sujeito a partir de um olhar que incide sobre os espaços que cada um ocupa. Da mesma maneira, Lafayette também vai espiar o mundo através de uma "portinhola". 
Seja por meio do olhar do outro, ou tomando o seu olhar sobre o outro, Lafayette vê o mundo de escanteio, de soslaio, de longe, tendo a permissão apenas de mirar a vida de um lugar fixo, emparedado. Essa maneira a mais de deixar com que o personagem seja visto indica outra forma de controle sobre o estatuto de seu corpo, incitando a produção de um saber que prevê a invisibilidade do ficar de escanteio.

Dessa cadeia de acontecimentos também faz parte o que poderíamos tomar, a princípio, como um deslocamento hierárquico de Lafayette, situando-o em pé de igualdade com os outros personagens, o que, de fato, não acontece. Faço referência à forma com que Lafayette exalta o vestido de Sookie Stackhouse. Ainda que tome a palavra, sua enunciação serve como escada para dar visibilidade ao outro, tomando para si a função de um coadjuvante de comportamento superficial e fútil. Mais uma vez a gestão de seu comportamento tem o tom da moralidade das condutas, colocando Lafayette de escanteio no jogo das luzes da beleza e da inteligência que relevam os valores atribuídos a Sookie. Nesse círculo de dizeres, a fala individual de Lafayette promove uma fala social estereotipada da maneira de o gay ver e falar sobre o outro.

Observamos nessa sequência discursiva que não se 
trata apenas de apresentar um sistema de interdição e ao mesmo tempo de recusa de Lafayette. Mais relevante é o fato da constituição do escanteio ser o resultado de procedimentos de controle do saber sobre o sujeito gay, relegando-o a um espaço do lado de fora do convívio social, campo possivelmente dado pelo espaço fechado da cozinha. Entretanto, esse corpo deve ser útil e estar submetido às regras do trabalho. Mesmo que fora da esfera do modelo social, o corpo deve ser produtivo. Isso parece justificar o lugar social da profissão de Lafayette como cozinheiro. Assim fica a lição: não ultrapasse os limites que lhe demos, Lafayette, mas não deixe de produzir.

No caminhar dessas correlações, acredito que Charlaine Harris nos impõe dois modos de saber para se relacionar com o gay. Um é o desprezo pelo indivíduo, que a autora transforma em sujeito e imprime ao gay como a marca de um selo em uma folha de papel. Ao colocá-lo sempre à margem da história de sua narrativa, coloca-o à margem da história de nossas vidas. Outro é o modelo patriarcal cristão que Harris transmite e reforça. A autora desenha linhas bem definidas de uma sociedade sob um modelo padrão para o homem heterossexual, lugar do qual parece falar ao constranger as tintas coloridas com as quais pinta Lafayette. 
Os saberes que Harris levanta, portanto, coloca em ação mecanismos de gestão do corpo que devem atender a princípios sócio-heteronormativos. Evidentemente, a autora faz isso nos mostrando Lafayette como se dissesse como não devemos ser e existir nesse mundo. Os mecanismos de poder, não tão sutis assim, de sua escrita é, sem dúvida, parte de uma instituição conservadora e repressora, que acessa materialidades linguísticas que buscam reforçar e agradar uma normatividade hipócrita que deseja ter a cara da diversidade sexual e inclusão das diferenças para satisfazer uma política pública à qual não tem realmente o menor interesse em se vincular.

\section{POLÍTICA DO CORPO E DO DESAMOR: O EXCESSO}

Uma política é a revelação de movimentos que visam poderes no plano nacional e internacional, traduzem mecanismos econômicos e podem visar o exercício de liberdade ou o adestramento dos indivíduos, dependendo do lugar do qual nos pronunciamos. O tipo de prática sobre o corpo que vem sendo colocada por Harris parece reafirmar o corpo como lugar de exame, portanto, de submissão e coerção. "Na prática cristã da confissão o corpo é objeto de exame, e nada além disso" (FOUCAULT, 2010, p. 32). O corpo de Lafayette me parece estar sendo esquadrinhado nesse 
pequeno lugar que lhe coube na narrativa de Harris. Mas se o corpo na sua forma de exame confessa, o que a autora faz com que ele diga sobre si? Leiamos.

E era o cadáver de Lafayette que fedia tanto. (HARRIS, 2009, p. 14)

Alcee se perguntava se Lafayette tinha AIDS, se o vírus poderia de algum modo ter vazado para o banco do carro de Andy e sobrevivido ali. Se fosse ele, venderia o carro. (HARRIS, 2009, p. 19)

Ah, ele me contou sobre uma festa a que ele foi. - Tentei lembrar as palavras exatas. - Ele disse que tinha ido a uma casa onde rolavam joguinhos sexuais de todo tipo. (HARRIS, 2009, p. 20)

O corpo é instado a confessar sua condição, a revelar seus segredos íntimos, a desdobrar-se sobre o outro, frágil e controlado. O corpo, nos ensinará Foucault, aparece em Homero apenas para designar o cadáver. Sob essa perspectiva, é o cadáver que nos ensina que "temos um corpo, que esse corpo tem uma forma, que essa forma tem um contorno, que nesse contorno há uma espessura, um peso; em resumo, que o corpo ocupa um lugar" (FOUCAULT, 2009, p. 19). Que lugar ocupa o corpo-cadáver de Lafayette? O excesso dos odores, a invasão dos humores pelos gases em putrefação, confessam uma vida podre a partir do posicionamento do controle das moralidades da instituição cristã. 
No confessionário do uso dos prazeres do corpo, o indizível socialmente é avaliado, examinado e julgado com os versículos da ordem da destemperança. O perigo do jogo dos prazeres aparece ameaçado pela patologia da condenação, quando uma personagem se pergunta se Lafayette tem AIDS. A questão não se forma em si, mas em encadeamento a um cadáver cujos sentidos da sexualidade condenável exalam odores que fedem. Para, além disso, emerge dessa fala uma "gestão pelo Estado das técnicas de produção e de controle da vida" (HALPERLIN, 2000, p. 43). Assim, o corpo confessa sua subjugação ao estatuto social dos poderes políticos e execra o desbunde do excesso no prazer, colocando-lhe limites estritos e sexualmente contundentes.

Duas enunciações, dois exemplos da força que o desagrado do uso dos prazeres evoca. Não se enquadrar às grades do sexo provoca resistência às leis seculares da Igreja e o sujeito foge do controle das mãos escultoras do pai da moral preconcebida. Essa já é uma razão suficiente para desaprovação do uso de nossos prazeres, tomado como lugar da exacerbação, do descontrole e da luxúria. E esse é o fato que ronda o suspense da morte de Lafayette, envolvido com "joguinhos sexuais". Descobriremos no final de Vampiros em Dallas que ele fazia parte de um Clube do Sexo na nada pacata cidadezinha de Bon 
Temps. Colocado dessa maneira, Lafayette é visto como um corpo do sexo. É lido com uma prática excessiva do exercício sexual. É sentido como o espaço da desordenação moral e, acima de tudo, afetiva.

O ponto principal ao qual esse breve percurso que percorri me permite ver é o lugar do amor no que concerne aos discursos que se aglutinam na constituição do sujeito Lafayette. O que pode talvez incomodar em relação ao modo de vida de nosso personagem? Dizer sobre seus gestos, roupas, falares, andares até parece uma maneira de compreendêlo e aceitá-lo livremente no seio das ações sociais de um gay. Entretanto, o discurso dos modos e maneiras de se ver Lafayette em Morto até o amanhecer e Vampiros em Dallas focaliza o seu corpo enquanto objeto de ato sexual. Ao agir dessa maneira, Harris afasta de seu corpo a possibilidade da homossexualidade como forma de invenção de si mesmo e não como afirmação de uma atitude sexual.

"Imaginar um ato sexual que não se conforma à lei ou à natureza, não é isso que inquieta as pessoas. Mas que os indivíduos comecem a se amar, eis o problema" (FOUCAULT, 2010, p. 349). Harris não deixa Lafayette amar. O sujeito gay é reduzido ao ato, e o afeto lhe é extirpado. Toda a cadeia que as sequências da narrativa de Harris colocam 
em funcionamento fala do lugar do desejo, sufocando uma discussão do prazer, da produção amorosa na constituição das identidades. A homossexualidade deveria ser um momento na história para se deixar ventilar os inter-relacionamentos e as afetividades. Ao invés disso, o discurso de Harris é cruel, cria um gay seco, um corpo para o sexo, um corpo que está à margem, de escanteio, um corpo cheio de gozo putrefato, no excesso, um corpo modelo para ser seguido em razão do que não se deve ser.

A política de Harris é, portanto, a do desamor. Contraditório até para um raciocínio tão cristão, mas muito adequado às apropriações de um poder com vistas à homogeneização. Harris parece desconhecer que "ser gay é, creio, não se identificar com os traços psicológicos e com as máscaras visíveis do homossexual, mas procurar definir e desenvolver um modo de vida" (FOUCAULT, 2010, p. 231). E, sem dúvida, praticar modos de vida cada uma à sua maneira, em estreiteza e singularidade.

\section{O CORPO DA BICHA PRETA: SÍNTESE FINAL}

O corpo está sempre sendo mobilizado em um campo no qual intervêm os mesmos canteiros de exercício para o sujeito. A emergência e circulação de um tipo de discurso se espalham por meio de instrumentos do poder e de seus 
"modos de aplicação" (REVEL, 2005, p. 67). É nesse domínio que destaco a forma de se designar Lafayette como a "bicha preta". A pergunta que me move é: qual é a rede na qual se desenha a história do corpo entre a visibilidade da homossexualidade e a etnia de um sujeito hoje?

As duas denominações, bicha e preta, respondem a uma forma de se pensar e viver a sexualidade e a posição do negro já na primeira década do século XXI. Imprimir tais posições a um sujeito leva à análise e a problematizações que dizem respeito a certo tipo de governo que se quer como regra para uma sociedade civil. Insulto, menosprezo e segregação acabam sendo menos importantes enquanto fala do que como procedimentos e táticas institucionais na sistematização de uma complexa rede de poder para a população. Cheguei a essas considerações depois de observar dois momentos diferentes dos livros de Harris em torno de Lafayette, que dizem o seguinte:

Dawn nunca tinha se dado com Lafayette, fosse por ele ser preto ou por ser gay, eu não sabia... talvez pelas duas razões. Arlene e Charlsie apenas aceitavam o cozinheiro, mas não davam um passo maior no sentido de serem amigas. Mas eu sempre gostara de Lafayette porque ele levava o que devia ser uma vida muito difícil com verve e graça. (HARRIS, 2007, p. 230) 
Andy permitiu que uma bicha negra dormisse no carro dele? - Essa era Holly, franca e direta. (HARRIS, 2009, p. 16)

Como podemos observar há uma discrepância para a tradução do vocábulo "black" dos textos originais. Em Morto até o amanhecer (2007), o tradutor Chico Lopes, toma black e o considera como preto. Enquanto Índigo, que traduziu Vampiros em Dallas (2009), coloca black em português como negro. O que parece estar em jogo aqui é a concepção histórica do lugar do qual falam seus tradutores. No primeiro caso, "preto" enuncia o lugar do preconceito e da desqualificação, sob uma condição de possibilidade muito bem acertada, a meu ver. Já no segundo caso, parece-me haver uma hipercorreção do uso de black para atender a uma necessidade política transmutada em um sistema linguístico dado como correto. Convenhamos que a associação de bicha e negra como xingamento em uma mesma frase parece, ainda que politicamente correto, dissonante.

A contradição do uso da língua da tradução pelos reescritores da história em brasileiro aponta para uma ruptura que extrapola o linguístico. Duas posições se depreendem daí. Os tradutores, por sua vez, produzem um saber sobre o gay e sobre o negro ao mesmo tempo em que revelam um saber sobre esses sujeitos, que acabaram de 
passar pela máquina do controle do poder. Isso significa que o poder disciplina os corpos dos sujeitos, "a partir deles e sobre eles" (REVEL, 2005, p. 78). Como resultado, temos esse tipo de ruptura na língua que exige que os sujeitos produzam um discurso em torno de si, sobre si e para si.

Considerando que toda forma de poder atravessa os corpos, a língua afetada pela história desvela a existência do corpo acerca de suas sexualidades e seus afetos. Nada mais, nada menos, estamos diante de uma ciência da linguagem para a vida, um exercício de biopoder, que demanda nossa atenção e recuperação da história do corpo do homem homossexual, as suas formas de amar, sentir prazer e se relacionar com outros homens.

No final, estamos tratando com "corpos que querem poder" (CAMARGO, 2013, p. 7). E, com isso, a língua vai produzindo seus equívocos e deixando entrever exercícios de liberdade e resistência, mesmo que a produção discursiva de Harris sobre Lafayette e o sujeito resvalem à sujeição de uma normatização compulsória, cristã, homogeneamente heterossexual, fechada em uma identidade única de base, apagando as multiplicidades do amor e do prazer entre pessoas do mesmo sexo em corpos de multiplicidades de afetos. 


\section{REFERÊNCIAS}

CAMARGO, Fábio Figueiredo. "Corpos que querem poder". In: MILANEZ, Niton; FERNANDES, Cleudemar Alves; FERREIRA, Jaciane Martins (orgs.). Revista Eletrônica de Estudos do Discurso e do Corpo. Corpo e Sujeito. v.2, n.2. Jul-Dez/2013, p. 7-16. Vitória da Conquista: Edições Uesb, 2013.

COURTINE, Jean-Jacque. "Introduction. Impossible virilité". In: CORBIN, Alain; COURTINE, Jean-Jacqques; VIGARELLO, Georges. (orgs.) Histoire de la virilité. La virilité en crise? XXe-XXle siècle. Paris: Seuil, 2011, p.7-11.

FOUCAULT, Michel. "Da amizade como modo de vida." In: MOTTA. Manoel Barros (org.). Coleção Ditos e Escritos VI. Michel Foucault. Repensar a política. Trad. Bras. Ana Lúcia Paranhos Pessoa. 1ed. Rio de Janeiro: Forense Universitária, 2010, p. 348-353.

. Le corps utopique, les heterotopies. Paris: Nouvelles Éditions Lignes, 2009.

. A arqueologia do saber. Trad. Bras. Luiz Felipe Baeta Neves. 7ed. Rio de Janeiro: Forense Universitária, 2008.

. "Sexualidade e Política." In: MOTTA. Manoel Barros (org.). Coleção Ditos e Escritos V. Michel Foucault. Ética, sexualidade e política. Trad. Bras. Elisa Monteiro e Inês Autran Dourado Barbosa. 2ed. Rio de Janeiro: Forense Universitária, 2006, p. 26-36.

. História da sexualidade I. A vontade de saber. Trad. Bras. Maria

Thereza da Costa Albuquerque e J. A. Guilhon Albuquerque. 13ed. Rio de Janeiro: Edições Graal, 1999.

GINZBURG, Carlo. Sinais. Raízes de um paradigma indiciário. In: . "Mitos, emblemas, sinais. Morfologia e História". Trad. Bras.

Federico Carotti. São Paulo: Companhia das Letras, 1990.

HALPERLIN, David M. Saint Foucault. Trad. francesa Didier Eribon. Paris: EPEL, 2000.

HARRIS, Charlaine. Vampiros em Dallas. Trad. bras. Índigo. São Paulo: Arx, 2009. 
HARRIS, Charlaine. Morto até o amanhecer. Trad. bras. Chico Lopes. Rio de Janeiro: Ediouro, 2007.

MILANEZ, Nilton. Pistas e traços do corpo suspeito. Jailton, o estuprador de Itambé. In: GREGOLIN, maria do Rosário F.V.; KOGAWA, João Marcos M. (org.). Análise do discurso e semiologia: problematizações contemporâneas. São Paulo: Cultura Acadêmica, 2012, p. 81-97.

SEDWIG, Eve Kosofsky. Between men. English Literature and Male Homosocial Desire. United States of America: Columbia University Press, 1985.

REVEL, Judith. Foucault. Conceitos essenciais. Trad. bras. Nilton Milanez e Carlos Piovezani. São Carlos: Claraluz, 2005.

Nilton Milanez tem Pós-doutorado em Discurso, Corpo e Cinema pela Sorbonne Nouvelle - Paris 3. É Professor Titular do Departamento de Estudos Linguísticos e Literários da Universidade Estadual do Sudoeste da Bahia. Atua nos Programas de Pós-Graduação em "Linguística" e "Memória, Linguagem e Sociedade", na Uesb. É líder do Labedisco/CNPq - Laboratório de Estudos do Discurso e do Corpo. www.uesb.br/labedisco 